\title{
Expression of colony-stimulating factors and inflammatory cytokines in the uterus of CD1 mice during Days 1 to 3 of pregnancy
}

\author{
T. R. Sanford, M. De and G. W. Wood \\ Department of Pathology and Oncology, University of Kansas Medical Center, 39th and Rainbow. \\ Boulevard, Kansas City, KS 66103, USA
}

\begin{abstract}
Summary. Morphological and immunohistochemical analyses have documented the development of an acute inflammatory response, marked by the early appearance of granulocytes and later infiltration of mononuclear cells, in the uterus immediately after mating in mice. The response peaked on Day 1 and subsided by Day 3. In the present study, RNAs for macrophage colony-stimulating factor (CSF-1) and granulocytemacrophage colony-stimulating factor (GM-CSF) and for interleukin $1 \alpha$ (IL-1 $\alpha$ ), IL-1 $\beta$, interleukin 6 (IL-6) and tumour necrosis factor alpha (TNF- $\alpha$ ) were detected in uterine tissue on Day 1. With the exception of IL-6, which was higher on Day 3 than on Day 1 , and IL- $1 \alpha$, which was not reduced on Day 2, concentrations of cytokine mRNA decreased to Day 3. No bioactivity was detected for GM-CSF, granulocyte colonystimulating factor or IL-3, but CSF-1, IL-1, IL-6 and TNF- $\alpha$ were detected on Day 1 using bioassays. Changes in concentrations approximately paralleled those for mRNA. The concentrations of mRNA for CSF-1, IL-1, IL- 6 and TNF- $\alpha$ were higher on Day 1 of pregnancy than in the uteri of cycling mice $24 \mathrm{~h}$ earlier. The data are consistent with previous morphological observations demonstrating the expression of an acute inflammatory response in the mouse uterus after mating. Further, the data demonstrate the expression of genes for CSF-1, GM-CSF, IL- $1 \alpha$, IL- $1 \beta$, IL- 6 and TNF- $\alpha$ is induced in the uterus during mating.
\end{abstract}

Keywords: mating; interleukin 1; interleukin 6; tumour necrosis factor alpha; colony-stimulating factors; mouse

\section{Introduction}

Mating in nearly all mammalian species occurs during a restricted portion of the oestrous cycle, when circulating and tissue-associated concentrations of oestrogen and progesterone are highest. The major effect of this process is to co-ordinate ovulation with mating, increasing the probability that fertilization will occur (Shelesnyak, 1955; Psychoyos, 1973; Short, 1984). The cyclic physiological changes which generate this juxtaposition involve complex effects of oestrogen and progesterone on several tissues and organs and on several cell types within each organ. Mating itself produces an additional series of endocrinological and neuroendocrinological effects which affect the uterus, making it hospitable to the developing blastocyst. Local effects on the uterus result from complex interactions between systemic physiological changes and locally produced factors.

Introduction of semen into the vagina and uterus by mating initiates a series of striking cellular changes which are indistinguishable from a classical acute inflammatory response (Lobel et al., 1967). Polymorphonuclear leucocytes are recruited from the blood. They migrate through the endometrium, through the luminal epithelium and into the uterine lumen. This early granulocytic response is combined with a longer-lasting mononuclear infiltrate, which includes high numbers of 
macrophages, a few mast cells and a few lymphocytes. Phagocytic cells eliminate the semen during Days 1 and 2, and, in the absence of continued inflammatory stimuli, the uterus returns to a state in which there is little histological evidence for cells derived from bone marrow cells (Lobel et al., 1967). Recently, the cellular character of this response was confirmed using quantitative immunohistochemical techniques (De \& Wood, 1991).

Inflammation is the normal response to injury. It has an elimination phase, which is designed to identify and remove pathogens and damaged tissue, and a reparative phase, which involves generation of a cascade of inflammatory cytokines (Billingham, 1987; Leibovich \& Wiseman, 1988; Rappolee et al., 1988). Mating is not a pathological event; intercourse in mice and rats does not cause obvious damage to the vaginal or uterine epithelium. Components of semen are not pathological, and any immunological differences between mating partners would not be expected to stimulate an acute inflammatory response in virgin females. Uniformity of the response between individuals decreases the possibility that the inflammation is caused by infectious agents, which sometimes would be expected to be present. Nevertheless, acute inflammation occurs, and in the absence of an obvious pathological explanation, we reasoned that increased understanding of the mechanisms that underlie it could give an insight into its physiological significance.

Both the accumulation of inflammatory cells and the complex reparative processes involved in pathological inflammation are dependent on production of a cascade of diverse mediators, including cytokines. The current study was based on the rationale that increased understanding of events associated with pregnancy requires detailed analysis of the inflammatory changes at a molecular level. We reasoned that, if there were more inflammatory cells in the tissue and if those cells received functional stimuli, colony-stimulating factors (CSF), such as CSF-1, granulocyte (G-CSF), granulocyte-macrophage CSF (GM-CSF) and interleukin 3 (IL-3), and cytokine mediators of inflammatory events, such as IL-1, IL-6 and tumour necrosis factor $\alpha$ (TNF- $\alpha$ ) might be expressed in uterine tissue on Days 1 to 3 of pregnancy.

\title{
Materials and Methods
}

\begin{abstract}
Animals. Swiss CDI mice (7-8 weeks old) were purchased from Harlan/Sprague Dawley (Indianapolis, IN, USA) maintained and bred in the University of Kansas Animal Care Facility. To obtain timed pregnant females, one male was combined with two females, and the females were observed for the formation of a vaginal plug. The day of plug appearance was designated as Day I of pregnancy. BALB/c mice (4 6 weeks old) were obtained from Harlan/Sprague Dawley for use in IL-1 bioassays.
\end{abstract}

Detection and quantitation of $\boldsymbol{m} \boldsymbol{R} N \boldsymbol{A}$. Mice were killed by asphyxiation with $\mathrm{CO}_{2}$ and the uterus was removed and snap-frozen in liquid $\mathrm{N}_{2}$. Frozen tissue from at least ten mice was homogenized using a polytron and total RNA was isolated by the guanidine isothiocyanate method (Han et al., 1987). Poly (A) RNA was isolated from total RNA by adsorption to the elution from oligo (dt) cellulose (type 3) (Aviv \& Leder, 1972). Clones of cDNA for murine IL-3, GM-CSF, G-CSF and CSF-1 (Metcalf, 1989) and IL-l $\alpha$ (Lomedico et al., 1984), IL-1 $\beta$ (Huang et al., 1988), IL-6 (molL-6; DNAX Research Institute of Molecular and Cellular Biology, Palo Alto, CA, USA) and TNF $\alpha$ (Genentech, Inc., San Francisco, CA, USA) were obtained and subcloned into pSP6 or pGEM vectors (Promega Biotech, Inc., Madison, WI, USA). Antisense RNA probes were synthesized using [ $\left.{ }^{32} \mathrm{P}\right] \mathrm{GTP}(>600 \mathrm{Ci} / \mathrm{mmol})$ and had specific activities in the range of $24 \times 10^{8} \mathrm{~d} . \mathrm{p} . \mathrm{m} . / \mu \mathrm{g}$ (Melton et al., 1984). Cytokine-specific mRNA was localized by Northern blotting (Andrews et al., 1987). The positive control for all of the cytokine probes except GM-CSF was total RNA obtained from $\mathbf{J} 774$ cells stimulated with lipopolysaccharide (LPS) from Escherichia coli. J774 is a macrophage cell line, which was obtained from the American Type Culture Collection, Bethesda, MD, USA. LPS stimulation was performed by growing $\mathrm{J774}$ cells in suspension, exposing growing cells $\left(10^{6}\right.$ cells $\left./ \mathrm{ml}\right)$ to LPS $(100 \mathrm{ng} / \mathrm{ml})$ for $3 \mathrm{~h}$ and collecting cells by sedimentation. RNA was extracted from a total of $5 \times 10^{8}$ cells. RNA extracted from normal mouse lung functioned as the positive control in Northern blot analyses using the GM-CSF probe.

Cytokine quantitation. Animals were killed by asphyxiation with $\mathrm{CO}_{2}$. Uteri were immediately removed and frozen in liquid $\mathrm{N}_{2}$. Uteri from at least five mice were pooled, thawed, homogenized in RPMI 1640 using a Dounce homogenizer and sedimented by centrifugation at $27000 \mathrm{~g}$ for $20 \mathrm{~min}$. The supernatant was removed and sterilized by filtration. The supernatants were then analysed for cytokine activity using bioassays. Activity of CSF was measured by assessing proliferation of cultured adult mouse bone marrow cells. Recombinant human CSF-1 (Cetus Corp., Emeryville, CA, USA), recombinant human GM-CSF (Immunex Corp., Seattle, WA, USA) and recombinant human 
IL-3 (Genzyme Corp., Cambridge, MA, USA) served as positive controls. Bone marrow cells failed to survive in wells containing no growth factor. The lower limit of sensitivity of the assay was 2 units of CSF-1. Since the endpoint in this assay was visual and the concentration of CSF-1 was semiquantitative, statistical analysis was not performed. The nature of the proliferating cells was determined by morphological examination of cultured cells in Wright's stained cytocentrifuge preparations. Specificity of cell proliferation was determined by inhibition of proliferation with cytokine-specific antibody. Each sample was assayed in triplicate. Each sample was assayed twice.

IL-1 was quantitated by a modification of the standard thymocyte proliferation stimulation assay (Wood $e t$ al., 1988). IL-1 was quantitated by its ability to augment thymocyte proliferation in the absence of exogenous mitogens. Specificity was determined by inhibition of activity with polyclonal antimouse IL-1 (Genzyme Corp.). Recombinant human IL-I $\alpha$ (Immunex Corp.) served as the positive control. Each sample was assayed in quadruplicate. Each sample was assayed twice.

IL-6 was assayed using the B9 cell line that is dependent on IL-6 (Helle et al.. 1988). Samples were assayed in triplicate and the assays were repeated with nearly identical results. These assays were performed on one set of supernatants derived from a pool of five mice/day. For that reason and because the assays were performed elsewhere, statistical analysis was not applied to the data.

TNF- $\alpha$ was assayed by the standard L929 cytotoxicity method (Mossman, 1983). Specificity was determined by inhibition of activity with polyclonal anti-mouse TNF- $\alpha$ (Genzyme Corp.). Recombinant human TNF- $\alpha$ was used as the positive control. Each sample was assayed in triplicate. Each sample was assayed on at least two separate occasions.

Statistics. Statistical evaluations were performed using one-tailed Student's $t$ test.

\section{Results}

\section{Expression of biologically active colony-stimulating factors and cytokines in the uterus}

To demonstrate local cytokine gene transcription and translation, mRNA was quantitated in uterine tissue on Days I to 3 using Northern blot analysis with cytokine-specific antisense RNA probes. IL-3 and G-CSF mRNAs were not detected. GM-CSF mRNA was evident on Day 1, but not on Days 2 or 3 (Fig. 1). The $4.6 \mathrm{kbp}$ form of CSF-1 mRNA was expressed at high concentration on Days $1-3$, but the $2.3 \mathrm{kbp}$ form was expressed at high concentrations on Days 1 and 2 and was barely detectable on Day 3 (Fig. 1).

Messenger RNA for IL- $1 \alpha$ and IL- $1 \beta$ was expressed at very high concentrations on Day 1 (Fig. 2). IL-1 $\alpha$ mRNA remained high on Day 2, but was undetectable by Day 3, while I1-1 $\beta$ decreased from Day 1 to Day 3 (Fig. 2). IL-6 mRNA was also high on Day 1, but, unlike the other cytokine mRNAs, it was not detected on Day 2, then was re-expressed on Day 3 (Fig. 2). TNF- $\alpha$ mRNA was expressed at high concentrations on Day 1 and decreased from Day 1 to Day 3 (Fig. 2).

CSF-1 bioactivity was detected in the uterus on Day 1, but was not present on Days 2 and 3 (Table 1). There was no evidence for any other colony-stimulating activity (IL-3, G-CSF or GMCSF) in the uterus on Days 1 to 3. IL-1 bioactivity was detected on Days 1 to 3 (Table 1). IL-1 activity decreased significantly from Day 1 to Day $2(P \leqslant 0.005)$ and increased significantly from Day 2 to Day $3(P \leqslant 0.005)$. IL-6 activity also was higher on Day 1 than on Day 2 (Table 1$)$. Like IL-1, TNF- $\alpha$ activity decreased significantly from Day 1 to Day $2(P \leqslant 0.001)$ and increased from Day 2 to Day $3(P \leqslant 0 \cdot 001$; Table 1$)$.

\section{Concentration of cytokine in uteri of cycling and pregnant mice}

On Day 1 of pregnancy, the concentrations of mRNA for GM-CSF, CSF-1, IL-1 $\beta$, IL-6 and TNF- $\alpha$ were considerably higher than during the oestrous cycle (Fig. 3). GM-CSF mRNA was not detectable at all in the uterus of cycling mice, while each of the others was expressed at much higher concentrations than during pro-oestrus or oestrus (Fig. 3). The concentration of IL-1 $\alpha$ mRNA expressed during oestrus was not obviously different from that expressed on Day 1 of pregnancy. By Day 3 of pregnancy, the mRNA for each of the cytokines, except $4.6 \mathrm{kbp}$ CSF-1, had returned to concentrations similar to those expressed during the oestrous cycle.

Although the concentration of mRNA for each cytokine was considerably higher on Day 1 than during pro-oestrus, tissue concentrations of cytokine bioactivity were not uniformly higher (Table 1). Thus, CSF-1 bioactivity in the uterus on Day 1 was approximately the same as during 

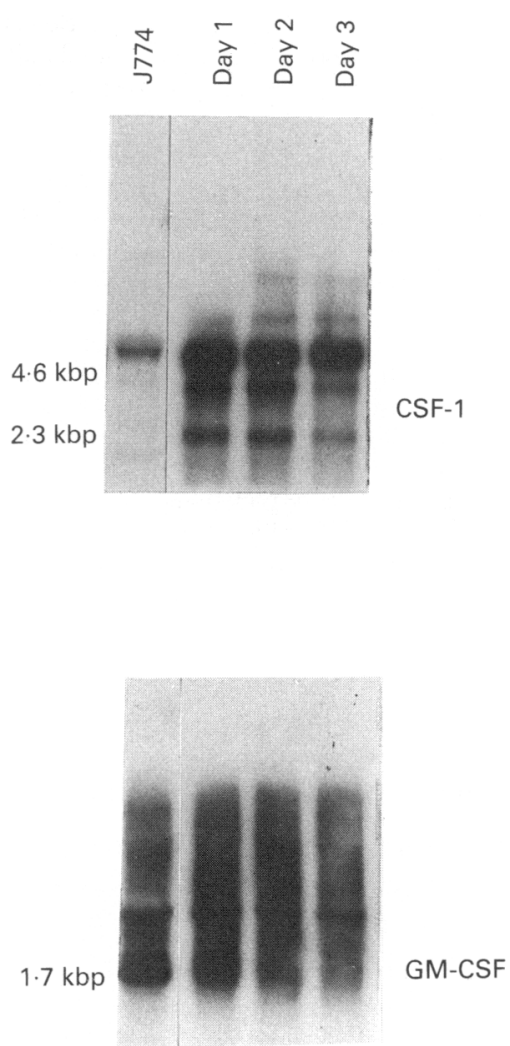

Fig. 1. Northern blot analyses for mouse granulocyte-macrophage colony-stimulating factor (GM-CSF) and macrophage colony-stimulating factor (CSF-1). The J774 lane contains RNA extracted from normal mouse lung as the positive control for GM-CSF and RNA extracted from lipopolysaccharide-stimulated $\mathrm{J} 774$ cells (macrophage cell line) for CSF-1. Lanes 2, 3 and 4 contain uterine poly (A) RNA from mice killed on Days 1 to 3 of pregnancy. Note that the macrophage cell line only made the $4.6 \mathrm{kbp}$ form of CSF-1 mRNA, while the 4.6 and $2.3 \mathrm{kbp}$ forms were made by uterine cells.

pro-oestrus, when cytokine concentrations are highest. The concentration of IL-1 was only slightly higher on Day $1(P \leqslant 0 \cdot 01)$. IL-6 bioactivity was markedly greater, and TNF- $\alpha$ activity was significantly higher $(P \leqslant 0.01)$ on Day 1 of pregnancy than during the oestrous cycle (Table 1$)$.

\section{Controls}

All bioassays and Northern blots were performed with a positive control. Northern blots were performed on poly (A) RNA to demonstrate that what was being detected was in the mRNA fraction. All bioassay results were confirmed by total inhibition of activity with specific antibody. All the studies, both bioassay and RNA, were repeated at least twice on tissue extracted by different individuals and were completely reproducible. Some of the results were confirmed using immunohistochemistry and hybridization in situ on tissue sections, but those studies are incomplete.

\section{Discussion}

Acute inflammation is a rapid cellular response to injury. The cellular effects are orchestrated by action of a combination of prostaglandins, leukotrienes, vasoactive amines, cytokines and other 


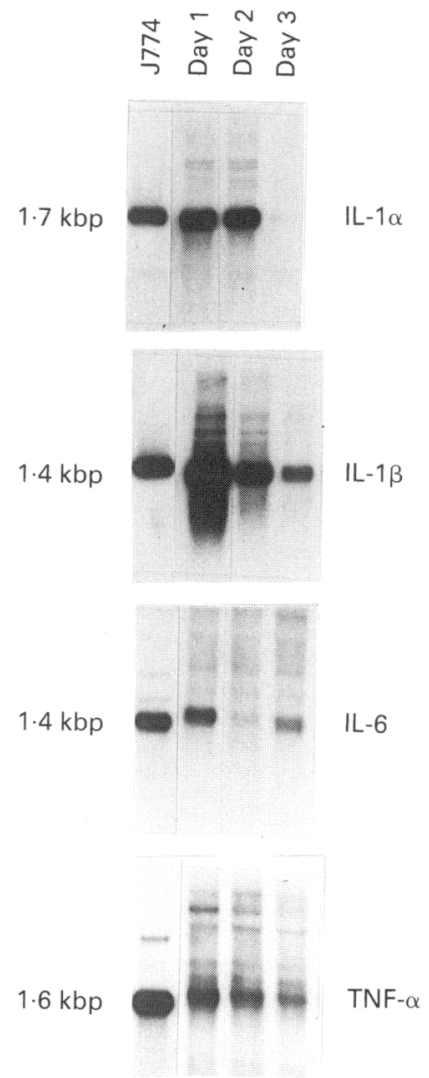

Fig. 2. Northern blot analyses for mouse interleukin $1 \alpha$ (IL-la), interleukin $1 \beta$ (IL-1 $\beta$ ), interleukin 6 (IL-6) and tumour necrosis factor $\alpha$ (TNF- $\alpha$ ). The J774 lane contains RNA extracted from lipopolysaccharide-stimulated $\mathbf{J} 774$ cells (macrophage cell line). Lanes 2, 3 and 4 contain uterine poly (A) RNA from mice killed on Days 1 to 3 of pregnancy.

Table 1. Quantitation of biologically active cytokine in soluble extracts of uterus from cycling mice

\begin{tabular}{lcccc}
\hline & $\begin{array}{c}\text { Macrophage colony- } \\
\text { stimulating factor* }\end{array}$ & Interleukin It & Interleukin 6+ & $\begin{array}{c}\text { Tumour necrosis } \\
\text { factor } \alpha \S\end{array}$ \\
\hline Pro-oestrus & 64 & $12 \cdot 9$ & $80 \cdot 4$ & 70 \\
Day 1 & 64 & $15 \cdot 3$ & $47 \cdot 7$ & 100 \\
Day 2 & ND & $6 \cdot 7$ & $7 \cdot 4$ & $<1$ \\
Day 3 & ND & $12 \cdot 7$ & $9 \cdot 7$ & 40 \\
\hline
\end{tabular}

* CSF-I concentrations are expressed as the reciprocal of the highest dilution at which the uterine supernatant sustained bone marrow cell proliferation.

+1L-1 concentrations are expressed as the mean c.p.m. $\times 10^{-3} \cdot 1 \cdot 0$ and $2 \cdot 0 \mathrm{ng}$ of recombinant human IL- $1 \alpha$ gave counts of 12.6 and $28 \cdot 7$, respectively. S.D. always $<20 \%$ of the mean.

$\$ 1 \mathrm{~L}-6$ values are expressed as units $/ \mu \mathrm{g}$ protein. S.D. always $<20 \%$ of the mean.

$\$ \mathrm{TNF} \alpha$ values are expressed as units $/ \mu \mathrm{g}$ protein. S.D. always $<20 \%$ of the mean.

rND, not detectable. 


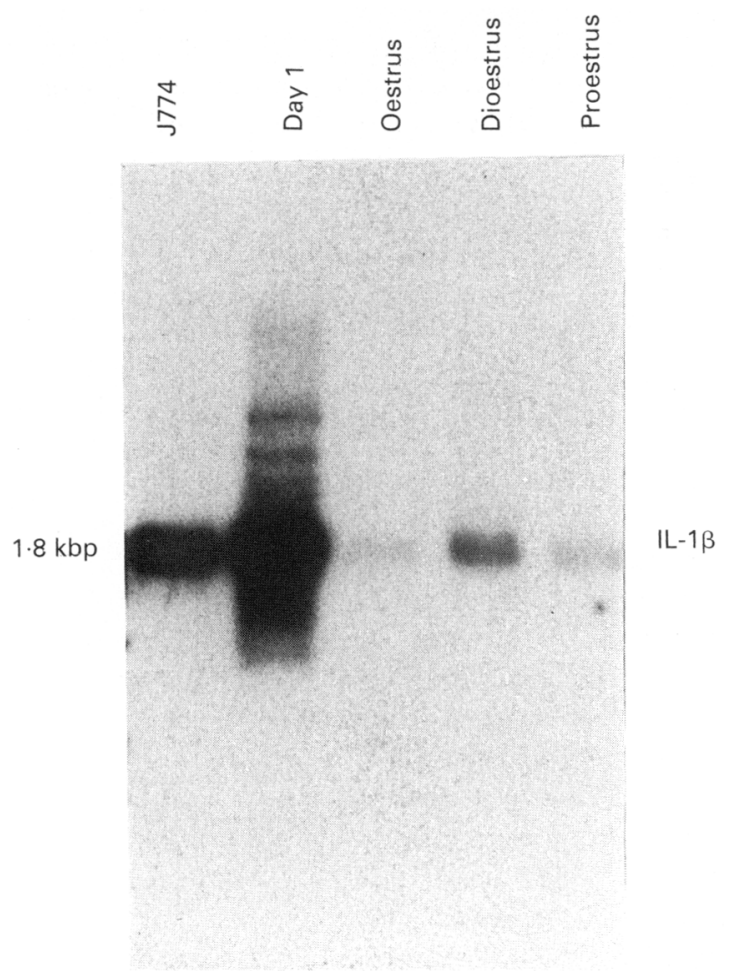

Fig. 3. Northern blot analysis for mouse interleukin $1 \beta$ (IL-1 $\beta$ ). The $J 774$ lane contains RNA extracted from lipopolysaccharide-stimulated $\mathrm{J} 774$ cells (macrophage cell line). Lane 2 contains uterine poly (A) RNA from Day 1 of pregnancy. Lanes 3, 4 and 5 contain uterine poly (A) RNA from normal mice during oestrus, dioestrus and pro-oestrus, respectively.

mediators (Billingham, 1987; Liebovich \& Wiseman, 1988; Rappolee et al., 1988; Wahl, 1988; Dinarello, 1989; Durum \& Oppenheim, 1989). The purpose of this response is local defence and tissue repair. As a normal physiological event, the cellular reaction which occurs in the uterus after mating appears to be an exception to the generally held view of acute inflammation as a defensive response to pathological stimuli.

The uterine cellular reaction is indistinguishable morphologically from a typical acute inflammatory response in that there is an early influx of granulocytes, followed by a mononuclear response, comprised principally of macrophages and lymphocytes (Lobel et al., 1967). We confirmed the cellular nature of the response using a combination of quantitative morphology and immunohistochemistry (De \& Wood, 1991). The present study demonstrated that the cellular events were associated with induction of a variety of cytokines which are usually associated with inflammation: GM-CSF, CSF-1, IL-1, IL-6 and TNF- $\alpha$. Not only was expression of the genes greater than in uteri from cycling mice, but also biologically active CSF-1, IL-1, IL-6 and TNF- $\alpha$ were detected. Coincident inflammatory cell accumulation and inflammatory cytokine production provides additional support for this being a typical acute inflammatory response.

Several discrepancies were noted between the expression of cytokine mRNA and cytokine bioactivity. The absence of detectable G-CSF $\mathrm{mRNA}$ and GM-CSF bioactivity is inconsistent with the high concentrations of granulocytes in the tissue at that time. However, granulocyte accumulation is unlikely to be due exclusively to local production of chemotactic factors, since both histological and immunohistological studies demonstrated granulocytes, but not macrophages, in the luminal, but not glandular, epithelium on Days 1 and 2. Granulocytes were specifically attracted to the lumen, not to the endometrium. Chemotactic factors induced within the tissue 
would attract cells into the tissue, but would not explain their migration into the lumen. The data suggest that seminal fluid contains a factor(s) which is specifically chemotactic for granulocytes. This explanation fails to account for expression of GM-CSF mRNA in the absence of granulocyte colony formation. Since granulocytes appear early, expression of GM-CSF mRNA in the absence of granulocyte colony stimulating factor activity could be because GM-CSF biological activity peaked before sampling. The possibility that the acute inflammatory response was induced by spermatozoa was exciuded by demonstrating that (i) pseudopregnancy (mating of females to vasectomized males) induces a qualitatively and quantitatively similar cellular reaction ( $R$. Choudhuri \& G. Wood, unpublished), (ii) pseudopregnancy also induces a similar cytokine response (R. Choudhuri, M. De \& G. Wood, unpublished) and (iii) the cellular response could not be reproduced by injecting semen (with or without spermatozoa) into the uterine lumen of cycling females (R. Choudhuri \& G. Wood, unpublished).

Another apparent discrepancy is that CSF-1, IL-1, IL-6 and TNF- $\alpha$ bioactivity was not appreciably higher than in the uteri of cycling mice, although concentrations of mRNA were much higher. There are several possible explanations for this observation. (1) Only soluble cytokine was assayed; there was no attempt to quantify cell-bound activity, which may have been considerably higher on Day 1 than on Day 0 because of increased receptor expression and more receptor positive cells. (2) Suppressor factors, such as prostaglandins and TGF- $\beta$, could have been in the supernatants and could have affected the read-out of the bioassays. (3) A likely explanation is that inflammatory responses are associated with increases in concentrations of proteolytic enzymes, which could have increased the breakdown of endogenous cytokine. (4) The explanation we favour is that bioactivity peaked early during the response and that negative regulation of cytokine production occurred at the translation level. Thus, while RNA continued to be transcribed in response to initial stimuli, the cytokines themselves induced negative regulatory factors, such as prostaglandins or TGF- $\beta$, which inhibited cytokine production, but failed to block mRNA synthesis. This is not easily tested, because of the difficulty in fixing the mating time precisely. Since there are no similar studies of inflammatory cytokine expression during acute inflammatory responses to pathological stimuli, it is not clear whether the concentrations or kinetics observed here are comparable.

The expression of CSF-1, which is a powerful macrophage chemoattractant (Wang et al., 1988; Pierce $e t a l ., 1990$ ), is consistent with the appearance of large numbers of macrophages in the uterus on Days 1 and 2. These were identified and quantified in both histological and immunohistological studies (Lobel et al., 1967; De et al., 1991). The progressive decrease in the $2 \cdot 3 \mathrm{kbp}$ form of uterine CSF-1 seen from Day 1 to Day 3 is consistent with the number of uterine macrophages being substantially reduced on Day 3 (De et al., 1991). The cellular source for the uterine CSF-1 during that time remains to be determined, but the primary source, particularly for the $2.3 \mathrm{kbp}$ form, is likely to have been uterine epithelial cells (Bartocci et al., 1986; Pollard et al., 1987; Arceci et al., 1989). The production of CSF-1 could also account for the localization pattern for the macrophages, which accumulated in subepithelial stroma (De et al., 1991).

The induction of the cytokines IL-1, IL- 6 and TNF- $\alpha$, which are associated with inflammation (Dinarello, 1989; Durum \& Oppenheim, 1989), provides additional evidence that what is being observed is a classical acute inflammatory response. The presence of large numbers of macrophages in the tissues and the association of these cytokines with macrophages increases the likelihood that these uterine cytokines were produced by macrophages during the development of the response. However, in the absence of cell separation and/or in-situ hybridization studies, it is not possible to exclude other cell types as a source for any or all of the cytokines. Both the accumulation of inflammatory cells and their apparent activation to produce inflammatory cytokines is surprising in the absence of obvious pathology.

We would like to thank G. K. Andrews for extensive help and advice. cDNA clones for IL-3, GM-CSF, G-CSF and CSF-1 were generously provided by D. Metcalf (Walter and Eliza Hall Institute, Melbourne, Australia). A cDNA clone for murine IL-1 $\alpha$ was generously provided by 
Hoffmann-La Roche, Inc. A cDNA clone for murine IL-1 $\beta$ was generously provided by J. Huang (E. I. duPont de Nemours \& Co.). IL-6 bioassays were generously performed by $M$. Kluger, University of Michigan, Ann Arbor, MI, USA.

\section{References}

Andrews, G.K., Lehman, L.D., Huet, Y.M. \& Dey, S.K. (1987) Metalothionein gene regulation in the preimplantation rabbit blastocyst. Development 100, 463-465.

Arceci, R.J., Shanahan, F., Stanley, E.R. \& Pollard, J.W. (1989) Temporal expression and location of colony stimulating factor 1 (CSF-1) and its receptor in the female reproductive tract are consistent with CSF-1regulated placental development. Proc. Natl Acad. Sci. USA 86, 8818 8822.

Aviv, H. \& Leder, P. (1972) Purification of biologically active globin messenger RNA by chromatography on oligothymidylic acid cellulose. Proc. Natl Acad. Sci. USA 69, 1409-14I2.

Bartocci, A., Pollard, J.W. \& Stanley, E.R. (1986) Regulation of colony-stimulating factor-1 during pregnancy. J. exp. Med. 164, 956961

Billingham, M.E.J. (1987) Cytokines as inflammatory mediators. Br. Med. Bull. 43, 350-370.

De, M., Choudhuri, R. \& Wood, G.W. (1991) Determination of the number and distribution of macrophages, lymphocytes and granulocytes in the mouse uterus from mating through implantation. J. Leuk. Biol. 10, 252-262.

Dinarello, C.A. (1989) Interleukin I and its biologically active cytokines. Adv. Immunol. 44, 153-205.

Durum, S. \& Oppenheim, J.J. (1989) Macrophagederived mediators: interleukin 1, tumor necrosis factor, interleukin 6. interferon and related cytokines. In Fundamental Immunology, pp. 639-661. Ed. W. E. Paul. Raven Press Ltd, New York.

Han, J.H., Stratona, C. \& Rutter, W.J. (1987) Isolation of full-length putative rat lysophospholipase cDNA using improved methods for mRNA isolation and CDNA cloning. Biochemistry 26, 1617-1625.

Helle, M., Brakenhoff, J.P.J., deGroot, E.R. \& Aarden, L.A. (1988) Interleukin 6 is involved in interleukin-1induced activities. Eur. J. Immunol. 18, 653-656.

Huang, J.J., Newton, R.C., Ruttledge, J., Huruk, R., Matthew, J.B., Covington, M. \& Lin, Y. (1988) Characterization of murine IL-1 $\beta$. J. Immunol. 140, $3838 \cdots 3843$.

Leibovich, S.J. \& Wiseman, D.M. (1988) Macrophages, wound repair and angiogenesis. In Growth Factors and Other Aspects of Wound Healing: Biological and Clinical Implications, pp. 131-145. Eds A. Barbul, E. Pines, M. Caldwell \& T. K. Hunt. Alan R. Liss, Inc., New York.

Lobel, B.L., Levy, E. \& Shelesnyak, M.C. (1967) Studies on the mechanism of nidation: Dynamics of cellular interactions during progestation and implantation in the rat. ACTA Endocr. (Suppl.) 123, 7-45.

Lomedico, P.T., Gubler, U., Hellman, C.D., Dukovich, M., Giri, J.G., Pan, Y.-C.E., Collier, K., Seminow, R., Chua, A.D. \& Mizel, S.B. (1984) Cloning and expression of murine interleukin-1 cDNA in Escherichia coli. Nature, Lond. 312, 458-462.
Melton, D.A., Krieg, P.A., Rebagliati, M.R., Maniatis, T., Zinn, K. \& Green, M.R. (1984) Efficient in vitro synthesis of biologically active RNA and RNA hybridization probes from plasmids containing a bacteriophage SP6 promoter. Nucl. Acids Res. 12, 70357057.

Metealf, D. (1989) The molecular control of cell division, differentiation commitment and maturation in haemopoietic cells. Nature, Lond. 339, 27-30.

Mossman, T. (1983) Rapid colorimetric assay for cellular growth and survival: Application to proliferation and cytotoxicity assays. J. Immunol. Meth. 65, 5503 .

Pierce, J.H., DiMarco, E., Cox, G.W., Lombardi, D., Ruggiero, M., Varesio, L., Wang, L.M., Choudhury, G.G., Sakaguchi, A.Y., DiFiore, P.P. et al. (1990) Macrophage colony stimulating factor (CSF-1) induces proliferation, chemotaxis, and reversible monocytic differentiation in myeloid progenitor cells transfected with the human $\mathrm{c}-\mathrm{fms} / \mathrm{CSF}-1$ receptor cDNA. Proc. Natl Acad. Sci. USA 87, 5613-5617.

Pollard, J.W., Bartocci, A., Arceclt, R., Orlofsky, A., Ladner, M.B., Stanley, E.R. (1987) Apparent role of the macrophage growth factor, CSF-I, in placental development. Nature, Lond. 330, 484486.

Psychoyos, A. (1973) Endocrine control of egg implantation. In Handhook of Physiology-Endocrinology II. Section 7, vol. II, Part 2, pp. 187-215. Eds R. O. Greep, E. B. Astwood \& S. R. Geiger. American Physiological Society. Washington DC.

Rappolee, D.A., Mark, D., Banda, M.J. \& Werb, Z. (1988) Wound macrophages express TGF $\alpha$ and other growth factors in vivo: analysis by mRNA phenotyping. Science, $N Y \mathbf{2 4 1}, 708711$.

Shelesnyak, M.C. (1955) Some experimental studies on the mechanisms of ova-implantation in the rat. Recent Prog. Horm. Res. 13, 269-322.

Short, R.V. (1984) Oestrous and menstrual cycles. Reproduction in Mammals: Hormonal Control of Reproduction, Book 3, pp. 115-152. Eds C. R. Austin \& R. V. Short. Cambridge University Press, New York.

Wahl, S. M. (1988) Fibrosis: bacterial-cell-wall-induced hepatic granulomas. In Inflammation: Basic Principles and Clinical Correlates, pp. 841860 . Eds J. I. Gallin, I. M. Goldstein \& R. M. Snyderman. Raven Press Ltd, New York.

Wang, J.M., Griffin, J.D., Rambaldi, A., Chen, Z.G. \& Mantovani, A. (1988) Induction of monocyte migration by recombinant macrophage colony stimulating factor. J. Immunol. 141, 575-579.

Wood, G.W., Kamel, S. \& Smith, K. (1988) Immunoregulation and prostaglandin production by mechanically and enzyme-derived murine decidual cells. $J$. Reprod. Immunol. 13, 235-248. 